\title{
Self-critical Rumination and Associated Metacognitions as Mediators of the Relationship Between Perfectionism and Self-esteem
}

\author{
Monica Fearn ${ }^{1} \cdot$ Claudia Marino $^{2} \cdot$ Marcantonio M. Spada ${ }^{1}$. \\ Daniel C. Kolubinski ${ }^{1}$ (D)
}

Accepted: 25 May 2021 / Published online: 17 June 2021

(c) The Author(s) 2021

\begin{abstract}
Past research has shown that perfectionism, can negatively impact self-esteem. However, the mediating factors that explain this relationship remain unclear. The current study aimed to investigate whether specific cognitive processes, namely, self-critical rumination and associated metacognitions, mediate this relationship. An opportunity sample of 347 participants completed a battery of online questionnaires measuring clinical perfectionism, self-critical rumination, metacognitions about self-critical rumination, self-esteem, and levels of psychological distress. Several hypotheses were tested to examine the associations between the study variables. Following this, a path analysis was used to determine whether the influence of perfectionistic concerns and perfectionistic striving on self-esteem is mediated by positive metacognitions about self-critical rumination, self-critical rumination, and negative metacognitions about self-critical rumination, serially. Positive metacognitions about self-critical rumination, self-critical rumination, and negative metacognitions about self-critical rumination partially mediated the relationship between perfectionistic concerns and self-esteem and fully mediated the relationship between perfectionistic striving and self-esteem. These results point towards possible interventions for those who struggle with low self-esteem due to their perfectionistic tendencies. Further investigations should explore additional factors that help to explain why perfectionism impacts self-esteem levels, whilst also addressing the limitations of this current research.
\end{abstract}

Keywords Perfectionism $\cdot$ Self-Esteem $\cdot$ Self-Critical Rumination $\cdot$ Metacognition

Daniel C. Kolubinski

kolubid2@1sbu.ac.uk

1 Division of Psychology, School of Applied Sciences, London South Bank University, London, UK

2 Dipartimento Di Psicologia Dello Sviluppo e Della Socializzazione, Universita' di Padova, Padova, Italy 


\section{Introduction}

A few central components arise in most definitions of perfectionism to emphasize that it involves both the setting of personally demanding standards (Hamachek, 1978) and evaluating oneself in accordance to whether these standards are achieved (Frost et al., 1991). Additionally, attention is likely to be focused on perceived failures rather than any successes accomplished (Hollender, 1965). To date, however, it remains unclear what impact of this process might be on one's overall evaluation of oneself and the mechanisms that might be involved in that impact.

\section{Perfectionism}

Different authors have debated whether perfectionism is a multidimensional (Frost et al., 1990; Hewitt \& Flett, 1991) or a unidimensional (Shafran et al., 2002) construct. Clarifying this, factor analytic studies have consistently found evidence for perfectionism having two higher-order dimensions, namely 'perfectionistic strivings' and 'perfectionistic concerns' (Bieling et al., 2004; Dickie et al., 2012; Frost et al., 1993; Stoeber \& Damian, 2014). Perfectionistic strivings capture the aspect of perfectionism that involves setting and pursuing exceedingly high standards for oneself. Whereas, perfectionistic concerns can be characterised by intense self-scrutiny and concern over one's mistakes, and additionally a preoccupation regarding others' judgements (Dunkley et al., 2006).

Differentiating between the two dimensions is important as research has shown that perfectionistic concerns have consistently been associated with negative outcomes including low self-esteem, heightened attachment fears, negative affect, and eating disorders (Dunkley et al., 2003; Dunkley et al., 2012; Frost et al., 1993; Pratt et al., 2001; Rice et al., 1998). Whereas, most research has shown perfectionistic strivings to be associated with positive outcomes such as better academic performance and problem solving skills (Blankstein et al., 2008; Flett et al., 1994; Frost et al., 1993). However, this being said, some studies have also found perfectionistic strivings to be associated with maladaptive outcomes, including increased anxiety and stress (Bieling et al., 2004; Dunkley et al., 2003). In summary, perfectionism is considered to be a two-factorial construct with both maladaptive and adaptive consequences (for a review see Stoeber \& Otto, 2006).

\section{Self-esteem}

A considerable body of research has investigated the concept of self-esteem, exploring its potential causes, consequences, and correlates (Marx \& Winne, 1978). To define simply, self-esteem refers to the extent that an individual likes themselves and believes they are a person of worth (Brown \& Marshall, 2006). It is a subjective measure, thus it does not necessarily reflect one's objective competencies and successes (Orth \& Robins, 2019). High self-esteem is characterised by an evaluation 
of oneself as worthy and likeable (Rosenberg, 1965), whereas low self-esteem is characterised by ambivalent or negative feelings towards the self (Baumeister et al., 1989).

Self-esteem is thought to remain relatively stable throughout the life span (Trzesniewski et al., 2003); however, occasional fluctuations may occur. This is because self-esteem can become contingent on certain domains such as academic ability, athleticism, popularity, etc. (Crocker \& Knight, 2005; Rosenberg et al., 1995; Woike \& Baumgardner, 1993). Therefore, one may only feel good about oneself by reaching a certain standard of excellence within a given domain (Crocker \& Knight, 2005; Park \& Crocker, 2013).

There has been a sizeable debate about the role self-esteem plays with respect to important life outcomes. Several authors have come to the conclusion that selfesteem may have limited importance for one's life circumstances (Baumeister et al., 2003; Crocker \& Park, 2004), whereas others have found evidence suggesting high self-esteem to be predictive of greater job satisfaction (Kuster et al., 2013), physical health (Stinson et al., 2008), relationship satisfaction, and emotional well-being (Orth et al., 2012).

Whilst low self-esteem, on its own, is not considered to be a psychological disorder, it often plays a part in numerous psychopathologies including; generalised anxiety disorder (Henning et al., 2007), major depressive disorder (Orth et al., 2009), eating disorders (Gual et al., 2002; Kugu et al., 2006), substance use disorder (Dooley et al., 2005) and schizophrenia (Barrowclough et al., 2003), to name a few. Overall, the evidence suggests self-esteem is likely to have a significant impact on the quality of life for many individuals.

\section{Perfectionism and Self-esteem}

Many authors have posited a link between perfectionism and self-esteem (Blatt, 1995; Hamachek, 1978; Horney, 1991; Sorotzkin, 1985). It is thought that the selfscrutiny and excessive concern that occurs for individuals displaying perfectionistic concerns produces a disparity between the idealised self and actual self. This disparity results in a more global negative view of the self, thus lowering self-esteem (e.g. Blankstein et al., 2008; Dunkley \& Grilo, 2007). In support of this, research has illustrated that increased perfectionistic concerns are associated with lower levels of self-esteem (Dunkley et al., 2012; Flett et al., 1991; Preusser et al., 1994; Rice et al., 1998).

Notably, Taylor et al. (2016) found that when individuals exhibit both perfectionistic concerns and perfectionistic strivings, the influence of perfectionistic concerns may diminish any positive effects that perfectionistic strivings would have had on the individual's self-esteem. For instance, individuals displaying high perfectionistic strivings and low perfectionistic concerns may have the ability to both strive for high standards and cope with mistakes that may occur. Whilst those exhibiting high perfectionistic strivings and perfectionistic concerns may find themselves experiencing conflict between striving for success and being unable to cope with any mistakes made (Hall et al., 1998; Parker, 1997). 


\section{Self-criticism and Self-critical Rumination}

Self-criticism can be defined as persistent, negative evaluations about oneself that occur when standards and expectations are not met (Shahar, 2015). High levels of self-criticism are strongly associated with low self-esteem (Dunkley \& Grilo, 2007; Grzegorek et al., 2004; Heimpel et al., 2002), depression (Zuroff et al., 1999) and many other forms of psychological distress (Werner et al., 2019). Research has also found self-criticism acts as a partial mediator in the relationship between clinical perfectionism and psychological distress (Dunkley et al., 2006; James et al., 2015). Nevertheless, some authors have pointed out that self-criticism 'in moderation' is not always detrimental, but may help individuals prevent future mistakes, allowing for personal improvement (Driscoll, 1989). Yet, if self-criticism does spiral into a ruminative style of thinking, this is deemed to be problematic in terms of one's psychological health. (Kolubinski et al., 2016, 2019; Smart et al., 2016).

Rumination is a repetitive and maladaptive thinking style regarding one's distress (Nolen-Hoeksema et al., 2008; Treynor et al., 2003). Hence, self-critical rumination can be defined as a persistent focus of attention on self-critical thoughts. This usually occurs without any attempt at problem-solving or altering one's circumstances (Smart et al., 2016). Research exploring self-critical rumination is still in its infancy. Nevertheless, it has been found that self-critical rumination is likely to influence the relationship between self-criticism and psychological distress (Kolubinski et al., 2017; Moreira \& Canavarro, 2018). Moreover, self-critical rumination has been found to be a significant predictor of self-esteem, even when controlling for age, levels of self-criticism, stress, anxiety, and depression (Kolubinski et al., 2019).

\section{Metacognitions about Self-critical Rumination}

Information that an individual holds regarding their own internal states and cognitions is defined as 'metacognition' (Wells, 2000). Over the past 30 years, there has been a large increase in the literature investigating the role of metacognition in psychological disorders (Wells, 2013). A model proposed by Wells and Matthews (1996), known as the Self-Regulatory Executive Function (S-REF) model, attempts to explain how metacognitions (beliefs about one's own thinking and how to control it) are involved in the development and maintenance of psychopathology. The model illustrates that psychopathology occurs due to a thinking style called the 'Cognitive Attentional Syndrome' (CAS), which consists of excessive worry, rumination, unhelpful and backfiring coping strategies, and attentional biases, such as selffocused attention and attention focused on threats. Two forms of metacognitionspositive and negative, are theorised to be responsible in activating and maintaining the CAS (Wells, 2013). Positive metacognitions are those concerned with the usefulness of engaging in the CAS as a way of improving one's performance and motivation (e.g., 'worrying will help me to avoid future problems'), whereas negative metacognitions involve beliefs that engaging in the CAS is both out of one's control and harmful (e.g., 'I can't control my thoughts'; Wells, 2009). Therefore, holding positive metacognitions about the CAS will activate this thinking style, leading to 
increased rumination and reduced problem solving. If one also holds negative metacognitions, the CAS will remain activated and unabated, fulling greater psychological distress (Wells \& Matthews, 1996).

The S-REF model has aided the understanding of processes involved in various forms of distress. Some examples include; depressive rumination (Papageorgiou \& Wells, 2001a, 2001b), problem gambling (Spada et al., 2014), problem drinking (Caselli \& Spada, 2013; Spada \& Wells, 2006) and anger (Simpson \& Papageorgiou, 2003). Similarly, the S-REF model can help explain the metacognitive processes responsible for the amplification and maintenance of self-critical rumination (Kolubinski et al., 2016), as research has found both positive and negative metacognitions to be predictive of self-critical rumination, even when levels of self-esteem, self-criticism and affect are controlled for (Kolubinski et al., 2017).

A recent study conducted by Kolubinski and colleagues (2019) explored the impact that self-critical rumination, and associated metacognitions, have on selfesteem. The model suggests that self-critical thoughts, when combined with positive metacognitions about self-critical rumination, would lead to the activation of self-critical rumination. If one simultaneously holds negative metacognitions about self-critical rumination, which is strongly associated with self-critical rumination, it will work to maintain that process of thinking. Prolonged exposure to this thinking style is likely to lower one's self esteem. Their findings supported this model, thus showing self-critical rumination and the associated metacognitions are likely to play a crucial role in predicting low self-esteem.

\section{Study Objectives and Hypotheses}

The aim of the current study was to investigate whether self-critical rumination, and associated positive and negative metacognitions, mediate the relationship between perfectionism and self-esteem. Previous literature has shown that perfectionistic concerns are associated with lower self-esteem (e.g. Dunkley et al., 2012; Flett et al., 1991; Rice et al., 1998), higher levels of self-criticism, and increased ruminative tendencies (James et al., 2015; O'Connor et al., 2007). Research has also found that both self-critical rumination and metacognitions about self-critical rumination play a significant role in predicting lower self-esteem (Kolubinski et al., 2019). What is less clear, however, is whether the self-critical rumination that occurs due to the associated positive and negative metacognitions mediates the relationship between perfectionistic concerns and self-esteem.

This research proposes that an individual who embodies a high level of perfectionistic concerns or perfectionistic striving is likely to hold positive metacognitions about self-critical rumination, which will lead to ruminating about self-critical thoughts. If the individual also holds negative metacognitions about self-critical rumination, this will serve to maintain self-critical rumination, impacting their selfesteem. This prediction is in accordance with the S-REF model (Wells \& Matthews, 1996).

In order to assess this, several hypotheses were tested. Firstly, it was hypothesised that self-esteem would be negatively correlated with perfectionistic concerns, 
perfectionistic striving, self-critical rumination, and both positive and negative metacognitions about self-critical rumination. Secondly, it was hypothesised that the other variables would be positively correlated with each other. Lastly, it was hypothesised that perfectionistic concerns and perfectionistic striving would indirectly influence self-esteem through the effect on positive metacognitions about self-critical rumination, self-critical rumination, and negative metacognitions about self-critical rumination, serially, and when controlling for levels of psychological distress.

\section{Method}

\section{Participants}

The sample consisted of 347 individuals ranging in age from 18 to 95 years old ( $M=41.58, S D=16.35,31$ chose not to respond). Recruitment of participants was carried out via opportunity sampling by advertising the study online using both social media platforms and the research participation scheme at London South Bank University. Individuals taking part in the study were required to be at least 18 years of age and be able to understand and communicate using English. A power analysis determined that a sample size of 103 participants was required in order to detect a medium effect size with a power of 0.80 .

\section{Self-report Measures}

\section{Clinical Perfectionism}

The Clinical Perfectionism Questionnaire (CPQ; Shafran et al., 2002) measures both perfectionistic strivings (CPQ-PS) and perfectionistic concerns (CPQ-PC). This questionnaire uses a 4-point Likert scale ranging from 1 ('not at all') to 4 ('all of the time'), with item 2 being reversed scored. Overall, higher scores indicate higher levels of clinical perfectionism. Participants are asked to report how they have felt 'over the past month' with questions such as, "Have you pushed yourself really hard to meet your goals?". The CPQ consists of 12 items, however, in the current study items 7 and 8 were removed. Item 7 was found to have a high cross-loading so it was not clear which factor this item measured and item 8 was found to be problematic when measuring clinical perfectionism in a non-clinical sample (Dickie et al., 2012). The resulting 10 items measure the two distinct dimensions of clinical perfectionism: (1) perfectionistic strivings, displaying good internal consistency $(\alpha=0.78)$; and, (2) perfectionistic concerns, showing satisfactory internal consistency $(\alpha=0.68)$.

\section{Self-critical Rumination}

The Self-critical Rumination Scale (SCRS; Smart et al., 2016) measures ruminative processes related to self-critical thoughts. This measure includes 10 items, each 
using a 4-point Likert scale ranging from 1 ('not at all') to 4 ('very much'). Higher scores on this questionnaire signify increased levels of self-critical rumination (e.g., "My attention is often focused on aspects of myself that I'm ashamed of". Three of the items $(\# 3,4,7)$, however, represent metacognitions about self-critical rumination (e.g., "Sometimes it is hard for me to shut off critical thoughts about myself"), so they were removed for the purpose of this study with a view to better distinguish between self-critical rumination and the metacognitions related to it. The resulting 7 questions of the modified version of the SCRS (SCRS-M) still maintained excellent reliability $(\alpha=0.91)$ and correlated very strongly with the original 10 -item version $(\mathrm{r}=0.98, p<0.001)$.

\section{Metacognitions about Self-critical Rumination}

The Metacognitions about Self-critical Rumination questionnaire (MSCRQ; Kolubinski et al., 2017) measures both positive (MSCRQ-P) and negative (MSCRQ$\mathrm{N})$ metacognitions associated with self-critical rumination. There are 10 items, each using a 4-point Likert scale from 1 ('do not agree') to 4 ('agree very much'). Items 2, 3, 5 and 7 assess the presence of MSCRQ-P (e.g., "I motivate myself to try harder by dwelling on stupid things I did in the past"). The MSCRQ-P subscale had a satisfactory internal consistency $(\alpha=0.68)$. Items $1,4,6,8,9$ and 10 assess MSCRQN (e.g., "I will get depressed if I don't stop reviewing my self-critical thoughts"). This subscale showed very good internal consistency $(\alpha=0.81)$ and correlates very strongly with the SCRS (Kolubinski et al., 2019).

\section{Self-esteem}

The Rosenburg Self-Esteem Scale (RSES; Rosenberg, 1965) is a widely used measurement of self-esteem. It includes 10 items, each using a 4-point Likert scale ranging from 0 ('strongly disagree') to 3 ('strongly agree'), with items 3, 5, 8, 9 and 10 being reversed in valence. A higher score indicates higher levels of self-esteem. Participants are asked to report how much they agree with each statement (e.g., "I feel that I'm a person of worth, at least on an equal plane with others.") This measure displayed excellent internal consistency $(\alpha=0.90)$.

\section{Psychological Distress}

The short form of the Depression Anxiety Stress Scale (DASS-21; Antony et al., 1998) measures general psychological distress, including symptoms of depression, hyperarousal and tension. It consists of 21 items, each using a 4-point Likert scale ranging from 0 ('Did not apply to me at all') to 3 ('Applied to me most of the time'). A higher score indicates higher levels of psychological distress. The questionnaire asked participants to report how much each statement (e.g., "I found it hard to wind down") applied to them over the past week. The DASS-21 displayed excellent internal consistency $(\alpha=0.92)$. 


\section{Procedure}

Ethical approval for this study was granted by the Division of Psychology Research Ethics Committee at London South Bank University. Participants were recruited via various social media platforms (Facebook, Instagram, Email, and WhatsApp) by sharing a hyperlink to the study website. Those who took part were encouraged to forward on the hyperlink to their own contacts in attempt to gather a wide range of participants. Additionally, the research participation scheme at London South Bank University was used to recruit undergraduate psychology students.

The hyperlink directed participants to the study website where they were presented with a participant information sheet explaining the purpose of the research, what it will entail, and details about anonymisation and confidentiality of responses. If consenting to take part, participants were presented with the following self-report measures to complete in order: DASS-21, CPQ, SCRS, MSCRQ, and lastly the RSES. Following completion of the questionnaires, the participants were thanked and debriefed.

\section{Data Analysis}

SPSS (version 26; IBM Corp., 2019) was used to conduct correlation analyses to test the associations between all variables in the study. A path analysis approach was then applied to test the association among study variables, using R (R Development Core, 2017) and single observed score for each construct. The two dimensions of perfectionism (CPQ-PS and CPQ-PC) were included as independent variables; positive metacognitions about self-critical rumination (MSCRQ-P), self-critical rumination (SCRS) and negative metacognitions about self-critical rumination (MSCRQN) as mediators; and self-esteem (RSES) as dependent variable. Psychological distress (DASS) was included in the model as covariate of RSES (Fig. 1). The age variable contained 31 missing values and was not included in the model in order to retain as many participants as possible in the path analysis. The robust maximum likelihood estimator (MLR; Satorra \& Bentler, 1994), suitable for non-normally

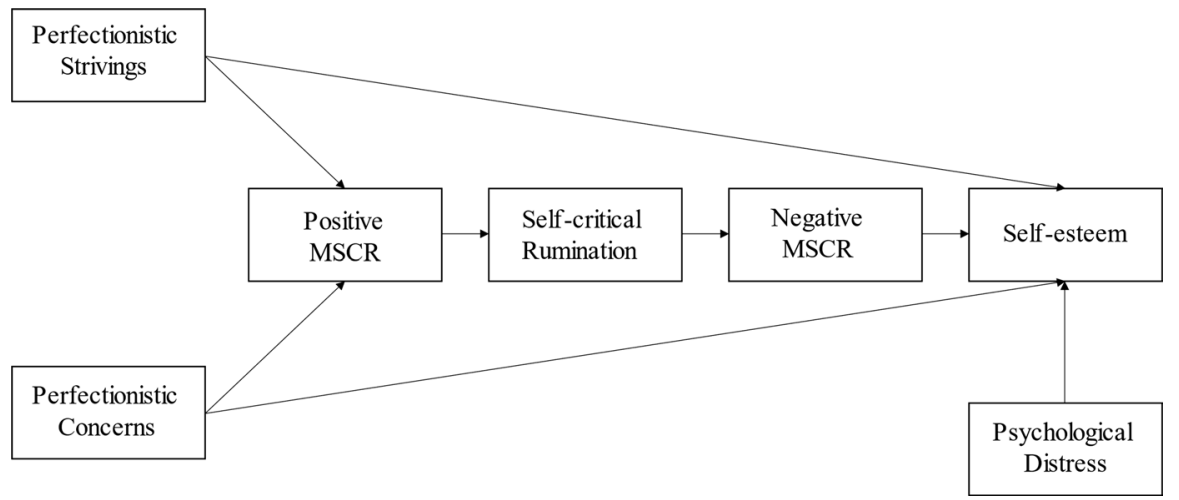

Fig. 1 Proposed theoretical model (MSCR = Metacognitions about Self-critical Rumination) 
distributed variables, was used. Indirect paths from the independent variables to the dependent variable via mediators were tested using the Sobel tests for mediation (Baron \& Kenny, 1986; Hayes, 2013). To evaluate the model fit, the explained variance of each endogenous variable (R2) and the total coefficient of determination (TCD; Jöreskog \& Sörbom, 1996) were considered.

\section{Results}

\section{Distribution of Data and Bivariate Correlations}

A series of Shapiro-Wilk normality tests showed that all variables were non-normally distributed at the $p<0.05$ level. Correlation analyses, using Spearman's Rho, were conducted to test the associations between all variables in the study. These variables included participant age, perfectionistic concerns (CPQ-PC), perfectionistic strivings (CPQ-PS), self-critical rumination (SCRS), positive metacognitions about self-critical rumination (MSCRQ-P), negative metacognitions about self-critical rumination (MSCRQ-N), self-esteem (RSES) and psychological distress (DASS). The means, standard deviations, and interquartile ranges are displayed in Table 1.

The analysis showed all study variables were significantly correlated with each other at the $\mathrm{p}<0.001$ level. As expected, significant negative correlations were found between RSES and CPQ-PC $\left(r_{s}=-0.66, p<0.001\right)$, CPQ-PS $\left(r_{s}=-0.32\right.$, $\mathrm{p}<0.001)$, SCRS $\left(\mathrm{r}_{\mathrm{s}}=-0.73, \mathrm{p}<0.001\right)$, MSCRQ-P $\left(\mathrm{r}_{\mathrm{s}}=-0.46, \mathrm{p}<0.001\right)$ and MSCRQ-N $\left(\mathrm{r}_{\mathrm{s}}=-0.72, \mathrm{p}<0.001\right)$. Additionally, significant positive correlations were found between the study variables CPQ-PC, SCRS, MSCRQ-P and MSCRQN (See Table 2).

Table 1 Means, standard deviations, medians, and interquartile ranges

\begin{tabular}{llrrrl}
\hline & & Mean & S.D & Median & Interquartile range \\
\hline 1 & Age & 41.51 & 16.37 & 42.00 & 29 \\
2 & CPQ-PC & 5.16 & 2.24 & 5.00 & 3.00 \\
3 & CPQ-PS & 8.05 & 3.45 & 8.00 & 4.00 \\
4 & SCRS-M & 9.47 & 5.59 & 9.00 & 9.00 \\
5 & MSCRQ-P & 3.59 & 2.36 & 3.00 & 3.00 \\
6 & MSCRQ-N & 4.72 & 3.72 & 4.00 & 5.00 \\
7 & RSES & 18.78 & 5.30 & 19.00 & 7.00 \\
8 & DASS-21 & 15.29 & 9.44 & 14.00 & 13.00 \\
\hline
\end{tabular}

$n$ 347; $* p<.05$. $* * p<.001$. CPQ-PC $=$ Clinical Perfectionism Questionnaire-Perfectionistic concerns; CPQ-PS = Clinical Perfectionism Questionnaire-Perfectionistic strivings; SCRS$M=$ Modified version of the Self-Critical Rumination Scale; MSCRQ-P = Metacognitions about Self-Critical Rumination ScalePositive; MSCRQ-N=Metacognitions about Self-Critical Rumination Scale-Negative; RSES = Rosenberg Self-Esteem Scale; DASS$21=$ Depression, Anxiety Stress Scale-21 
Table 2 Bivariate correlations

\begin{tabular}{|c|c|c|c|c|c|c|c|c|}
\hline & & 1 & 2 & 3 & 4 & 5 & 6 & 7 \\
\hline 1 & Age & - & & & & & & \\
\hline 2 & CPQ-PC & $-.35 * *$ & - & & & & & \\
\hline 3 & CPQ-PS & $-.30 * *$ & $.50 * *$ & - & & & & \\
\hline 4 & SCRS-M & $-.38 * *$ & $.70 * *$ & $.46 * *$ & - & & & \\
\hline 5 & MSCRQ-P & $-.30 * *$ & $.40 * *$ & $.44 * *$ & $.59 * *$ & - & & \\
\hline 6 & MSCRQ-N & $-.28 * *$ & $.62 * *$ & $.40 * *$ & $.75^{* *} *$ & $.57 * *$ & - & \\
\hline 7 & RSES & $.24 * *$ & $-.66^{* *}$ & $-.32 * *$ & $-.73 * *$ & $-.50 * *$ & $-.72 * *$ & - \\
\hline 8 & DASS-21 & $-.28 * *$ & $.60 * *$ & $.38 * *$ & $.64 * *$ & $.40 * *$ & $.55 * *$ & $-.56 * *$ \\
\hline
\end{tabular}

$n$ 347; ${ }^{*} p<.05 .{ }^{*} p<<.001$. CPQ-PC $=$ Clinical Perfectionism Questionnaire-Perfectionistic concerns; CPQ-PS $=$ Clinical Perfectionism Questionnaire-Perfectionistic strivings; SCRS-M=Modified version of the Self-Critical Rumination Scale; MSCRQ-P=Metacognitions about Self-Critical Rumination Scale-Positive; MSCRQ-N=Metacognitions about Self-Critical Rumination Scale-Negative; RSES $=$ Rosenberg Self-Esteem Scale; DASS-21 = Depression, Anxiety Stress Scale-21

\section{Assessing Multicollinearity}

Due to the high correlations listed above, the Variance Inflation Factors (VIF) were calculated for all predictor variables. No VIF exceeded the cut-off of 10 (Max =3.17; Kutner, Nachtsheim, \& Neter, 2004; Sheather, 2009). The original 10-item SCRS, however, resulted in VIFs between 5.5 and 5.8 when all but two predictor variables were used as the criterion (MSCRQ-N and DEQ-SC6), which questions the overlap in variance between self-critical rumination, its negative metacognitions and self-criticism.

\section{Path Analysis}

As shown in the Fig. 2, results of the path analyses revealed that all path coefficients were significant at the $p<0.001$ level, with the exception of the association between DASS and RSES $(\beta=-0.10, p<0.05)$ and the link between CPQ-PS and RSES that was not significant $(\beta=0.08, p=0.09)$. Conversely the other dimension of perfectionism (CPQ-PC) was directly associated with RSES.

Both CPQ-PS and CPQ-PC were positively associated with MSCRQ-P, which, in turn, was positively associated with SCRS. Moreover, SCRS was positively and strongly associated with MSCRQ-N, which, in turn, was negatively associated with the outcome variable (RSES).

With regards to indirect relationships, results of the Sobel test supported the mediating role of the three mediators between the two dimensions of perfectionism and self-esteem: namely, the indirect link between CPQ-PS and RSES via three mediators (MSCRQ-P SCRS MSCRQ-N) $(\beta=-0.075, \mathrm{SE}=0.023, \mathrm{z}=-4.487$, $p<0.001)$, and the indirect link between CPQ-PC and RSES via three mediators $(\beta=-0.037, \mathrm{SE}=0.047, \mathrm{z}=-2.803, p=0.005)$.

With regards to model fit, the model accounted for $51 \%$ of the variance for the outcome variable (RSES), $56 \%$ of the variance for one mediator (i.e. MSCRQ-N) 


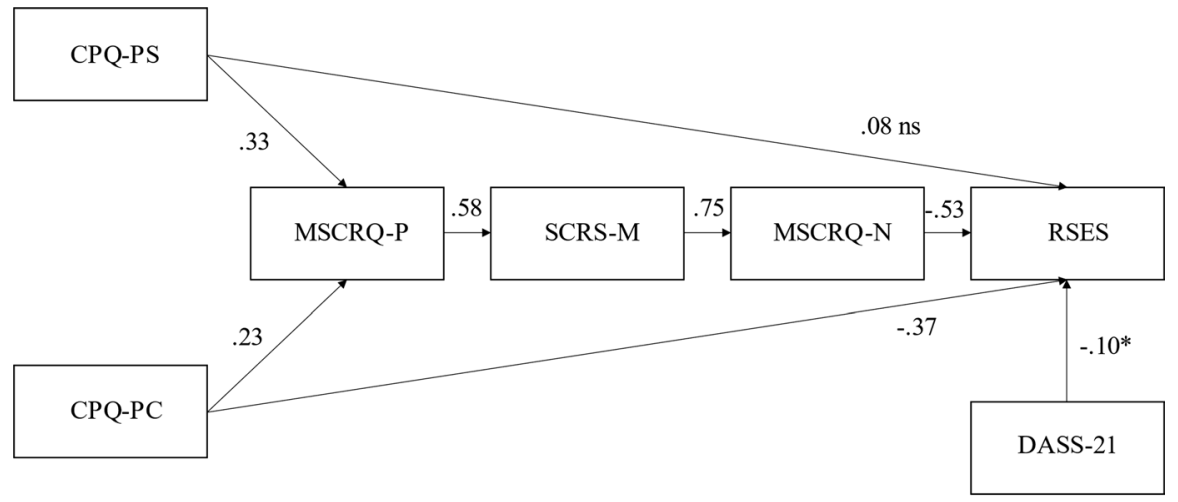

All $p<.001 ; *<.05$

Fig. 2 Results of the path analytical model. Notes: $n=316$; CPQ-PS $=$ Clinical Perfectionism Questionnaire-Perfectionistic strivings; CPQ-PC =Clinical Perfectionism Questionnaire-Perfectionistic concerns; MSCRQ-P=Metacognitions about Self-Critical Rumination Scale-Positive; SCRS-M=Modified version of the Self-Critical Rumination Scale; MSCRQ-N=Metacognitions about Self-Critical Rumination Scale-Negative; RSES=Rosenberg Self-Esteem Scale; DASS-21=Depression, Anxiety Stress Scale-21; All $p<.001 ; * p<.05$

variable. Lower variance was observed for the other mediators (e.g., 34\% for SCRS and $24 \%$ for MSCRQ-P). Finally, the total amount of variance explained by the model (Total Coefficient of Determination, TCD $=0.41$ ) indicated a good fit to the observed data. Indeed, this TCD corresponds to a correlation of $r=0.64$, which can be considered a medium to large effect size (Cohen, 1988).

\section{Discussion}

\section{Addressing the Aims of the Study}

The primary aim of this study was to investigate whether the influence of perfectionism, as distinguished by perfectionistic concerns and perfectionistic striving, on self-esteem was mediated, serially, by positive metacognitions about self-critical rumination, self-critical rumination, and negative metacognitions about self-critical rumination in accordance with the S-REF model (Wells \& Matthews, 1996).

Prior to investigating this mediation model, evidence was found supporting all other hypotheses stated at the outset of the research. Firstly, self-esteem was negatively correlated in the moderate to high range with perfectionistic concerns, perfectionistic striving, self-critical rumination, positive metacognitions about self-critical rumination and negative metacognitions about self-critical rumination. Secondly, perfectionistic concerns, perfectionistic striving, self-critical rumination, and metacognitions about self-critical rumination (positive and negative) were found to be positively correlated with one another. The majority of these associations have been 
apparent in previous literature (e.g. Dunkley et al., 2012; James et al., 2015; Kolubinski et al., 2016, 2017, 2019; Rice et al., 1998). However, until now evidence that perfectionism and self-critical rumination has not yet emerged in the literature. This finding enriches earlier research, as previous studies have found positive associations between perfectionistic concerns and other forms of rumination, such as 'brooding' rumination (Egan et al., 2014; O'Connor et al., 2007) and depressive rumination (Flett et al., 2002), but not self-critical rumination, which despite having similarities to other ruminative processes, is considered to be its own distinct construct (Smart et al., 2016).

In further support of the hypotheses, the path analysis indicated that both perfectionistic concerns and perfectionistic striving indirectly influenced self-esteem levels through their effect on positive metacognitions about self-critical rumination, selfcritical rumination, and negative metacognitions about self-critical rumination, in a sequential manner. In the case of perfectionistic concerns, which includes increased self-criticism, this implies that the presence of positive metacognitions about selfcritical rumination would activate self-critical rumination. If negative metacognitions about self-critical rumination are also present, this would further increase the difficulty in shifting attention away from self-critical thoughts as attempts at interrupting self-critical rumination would be discontinued or not initiated in the first place. Over time, as self-critical rumination becomes perseverative, adverse effects on self-esteem should ensue. These findings extend the existing literature, aligning themselves with the metacognitive model of self-esteem (Kolubinski et al., 2019), which is grounded in Wells and Matthews' (1996) S-REF model.

In support of the present findings, prior research has shown that those high in perfectionistic concerns tend to utilise maladaptive coping mechanisms, such as rumination, rather than active problem-solving, to deal with setbacks (Mouratidis \& Michou, 2011; Park et al., 2010). Rumination is an emotion-focused coping mechanism, which is utilised in the attempt to process and modify internal negative events, whereas problem-focused coping involves guiding action with the intention to alter one's external reality (Folkman, 2013; Wells \& Matthews, 1996). Coping via ruminative thinking, thus avoiding active problem-solving, means that self-critical cognitions go unchallenged. Consequently, the acquisition of new and effective skills are obstructed (Wells, 2000). This has been shown using experimental studies that have induced rumination in individuals experiencing distress. For example, Lyubomirsky and Nolen-Hoeksema (1995) found rumination to interfere with inter-personal problem solving and to have an adverse effect on mood. By virtue of the literature, the perfectionists' inclination to use rumination as a way of coping, is unhelpful and likely prolongs psychological distress.

Kolubinski et al. (2019), upholding the present findings, showed that prolonged exposure to self-critical rumination, linked to one's metacognitions, has the potential to negatively impact self-esteem. This is important to understand as lowered self-esteem may have further adverse effects on many important life outcomes (Orth et al., 2012; Trzesniewski et al., 2006). Two opposing theories are often highlighted in the literature, namely the 'scar model' and the 'vulnerability model' of self-esteem. The scar model states that negative affect impacts self-esteem levels, whereas the vulnerability model suggests low self-esteem leads to the development 
of distress (Orth et al., 2009, 2016; Shahar \& Davidson, 2003; Shahar \& Henrich, 2010). Both theories have been supported in the literature, and this relationship may be reciprocal. A greater evidence-base does favour, however, the vulnerability model (Ormel et al., 2004; Orth et al., 2009; Shahar \& Davidson, 2003; Sowislo \& Orth, 2013), signifying that low self-esteem is a strong risk factor for the development of psychological distress. This is crucial to understand, as interventions aimed at restructuring negative self-evaluation could prevent the development of further psychological distress.

Unlike perfectionistic striving, the present research also uncovered that perfectionistic concerns directly influenced self-esteem levels, independently of the other variables in the study. This suggests that the cognitive processes proposed to explain the relationship only partially mediate the effect of perfectionistic concerns on self-esteem levels. Therefore, it is likely there are more factors that will need to be understood to gain a full picture. One possible addition to the proposed pathways could be one's inter-personal relationships. Rumination has been thought to impair social relationships (Young \& Nolen-Hoeksema, 2001), and according to the Sociometer theory (Leary et al., 1995), self-esteem is dependent on the degree to which one is included by others, whereby rejection from one's peers will lead to lower self-esteem. Thus, if the individual starts to lose peer support due to excessive rumination, this may consequently impact their self-esteem levels. Future research may therefore wish to explore inter-personal relationships as an additional factor to the proposed pathway in this study. Other additional factors that are worth exploring include: parental pressure, schooling environment, socio-economic status, social inequalities, etc.

\section{Clinical Implications}

Results obtained from the present research have fostered a greater theoretical understanding of the pathways involved in explaining how perfectionistic concerns can lead to low self-esteem. These findings point towards therapeutic practices that are likely to benefit individuals by decreasing perfectionistic tendencies and rumination as a way of improving global self-evaluation.

A suitable intervention to consider is Metacognitive Therapy (MCT), which is theoretically grounded in the S-REF model (Wells \& Matthews, 1996). This therapy promotes recovery by modifying one's metacognitions that work to maintain the Cognitive Attentional Syndrome (CAS). The CAS is a maladaptive constellation of coping strategies including, but not limited to, thought suppression, rumination, excessive worry, threat monitoring and dwelling on the past (Wells, 2013). By identifying the metacognitions that maintain the CAS, the individual can learn to alter these and acquire novel ways in which to respond to negative intrusive thoughts. Some of the practices used in MCT include the attention training technique (Fergus \& Bardeen, 2016; Fergus et al., 2014; Knowles et al., 2016), detached mindfulness (Gkika \& Wells, 2015; Wells, 2005), worry mismatch and rumination postponement (Wells, 2013). These all work towards increasing the flexibility of how one responds when experiencing unhelpful cognitions. Evidence has shown promising effects of 
utilising MCT for psychological distress (Nordahl et al., 2017; Solem et al., 2009; Wells \& Colbear, 2012; Wells et al., 2010). Considering both the present and earlier research evidence, it is likely that MCT may provide a promising clinical application for individuals who struggle to separate themselves from their harmful perfectionistic, self-critical thinking.

\section{Limitations}

When interpreting the results of this research, several limitations ought to be considered. First, whilst the sample was diverse with respect to age, the participants' gender, ethnicity, and psychiatric history was not recorded in this study, therefore it is unknown whether the findings can generalise to all demographic groups or whether any of the participants have been involved in psychological treatment. Second, all data was collected via self-report questionnaires, meaning the results are subject to possible biases such as social desirability and context effects. Third, a cross-sectional design was used, thus posing limits when inferring a causal relationship between the variables. Fourth, it is uncertain that the self-report questionnaires accurately measured the constructs they set out to measure. In particular, the questionnaire items measuring positive metacognitions about self-critical rumination (MSCRQ) and perfectionistic concerns (CPQ) had a slightly lower Cronbach's alpha scores, suggesting there may be a problem with internal consistency. Additionally, the self-critical rumination scale (SCRS; Smart et al., 2016) includes three items that assess negative metacognitions. These items were not removed for this study, so it may be that the SCRS measured, in part, negative metacognitions rather than purely self-critical rumination. Fifth, opportunity sampling was used to recruit participants, thus it is possible the sample was not representative of the entire population. Sixth, this study did not control for potential confounding variables, such as socio-economic status, education, social relationships, support networks or being in psychological treatment. Lastly, the data was collected during the height of the COVID-19 pandemic, affecting individuals in a variety of ways, including selfreported measures of cognitive-affective states. Future studies should address these limitations.

\section{Conclusion}

The current research makes a substantial theoretical contribution to the understanding of how perfectionistic concerns can impact one's self-esteem via specific cognitive and metacognitive processes. The findings point towards clinical implications, such as the use of Metacognitive Therapy for individuals who struggle with low selfesteem due to perfectionism. Further investigations could extend this research by exploring other additional factors that help to explain why perfectionistic concerns impact self-esteem, whilst also addressing the limitations of the present study. To conclude, it may be possible to prevent individuals with perfectionistic tendencies 
from developing low self-esteem by altering the metacognitions that activate and maintain their self-critical rumination.

Author's Contribution Authors MF and DK designed the study, with input from MS, and MF collected the data. CM performed the path analysis and MF and DK wrote and revised the manuscript. All authors contributed to the final draft.

Funding No funding was received for the completion of this study.

Data Availability Data available on request.

\section{Declarations}

Conflict of interest The authors have no conflict of interest to declare.

Open Access This article is licensed under a Creative Commons Attribution 4.0 International License, which permits use, sharing, adaptation, distribution and reproduction in any medium or format, as long as you give appropriate credit to the original author(s) and the source, provide a link to the Creative Commons licence, and indicate if changes were made. The images or other third party material in this article are included in the article's Creative Commons licence, unless indicated otherwise in a credit line to the material. If material is not included in the article's Creative Commons licence and your intended use is not permitted by statutory regulation or exceeds the permitted use, you will need to obtain permission directly from the copyright holder. To view a copy of this licence, visit http://creativecommons.org/licen ses/by/4.0/.

\section{References}

Antony, M. M., Bieling, P. J., Enns, M. W., Swinson, R. P., Cox, B. J., Enns, M. W., \& Swinson, R. P. (1998). Psychometric properties of the 42-item and 21-item versions of the Depression Anxiety Stress Scales in clinical groups and a community sample. Psychological Assessment, 10(2), 176-181. https://doi.org/10.1037/1040-3590.10.2.176

Baron, R. M., \& Kenny, D. A. (1986). The moderator-mediator variable distinction in social psychological research: Conceptual, strategic, and statistical considerations. Journal of Personality and Social Psychology, 51(6), 1173.

Barrowclough, C., Tarrier, N., Humphreys, L., Ward, J., Gregg, L., \& Andrews, B. (2003). Self-esteem in schizophrenia: Relationships between self-evaluation, family attitudes, and symptomatology. Journal of Abnormal Psychology, 112(1), 92-99. https://doi.org/10.1037/0021-843X.112.1.92

Baumeister, R. F., Campbell, J. D., Krueger, J. I., \& Vohs, K. D. (2003). Does high self-esteem cause better performance, interpersonal success, happiness, or healthier lifestyles? Psychological Science in the Public Interest, 4(1), 1-44. https://doi.org/10.1111/1529-1006.01431

Baumeister, R. F., Tice, D. M., \& Hutton, D. G. (1989). Self-presentational motivations and personality differences in self-esteem. Journal of Personality, 57(3), 547-579. https://doi.org/10.1111/j.14676494.1989.tb02384.x

Bieling, P. J., Israeli, A. L., \& Antony, M. M. (2004). Is perfectionism good, bad, or both? Examining models of the perfectionism construct. Personality and Individual Differences, 36(6), 1373-1385. https://doi.org/10.1016/S0191-8869(03)00235-6

Blankstein, K. R., Dunkley, D. M., \& Wilson, J. (2008). Evaluative concerns and personal standards perfectionism: Self-esteem as a mediator and moderator of relations with personal and academic needs and estimated GPA. Current Psychology, 27(1), 29-61. https://doi.org/10.1007/s12144-008-9022-1

Blatt, S. J. (1995). The destructiveness of perfectionism: Implications for the treatment of depression. American Psychologist, 50(12), 1003-1020. https://doi.org/10.1037/0003-066X.50.12.1003 
Brown, J. D., \& Marshall, M. A. (2006). The three faces of self-esteem. In M. H. Kernis (Ed.), Selfesteem issues and answers: A sourcebook of current perspectives (pp. 4-9). Psychology Press.

Caselli, G., \& Spada, M. M. (2013). The metacognitions about desire thinking questionnaire: Development and psychometric properties. Journal of Clinical Psychology, 69(12), 1284-1298. https://doi. org/10.1002/jclp.21999

Cohen, J. (1988). Statistical power analysis for the social sciences. Lawrence Erlbaum Associates.

Crocker, J., \& Knight, K. M. (2005). Contingencies of self-worth. Current Directions in Psychological Science, 14(4), 200-203. https://doi.org/10.1111/j.0963-7214.2005.00364.x

Crocker, J., \& Park, L. E. (2004). The costly pursuit of self-esteem. Psychological Bulletin, 130(3), 392414. https://doi.org/10.1037/0033-2909.130.3.392

Dickie, L., Surgenor, L. J., Wilson, M., \& McDowall, J. (2012). The structure and reliability of the Clinical Perfectionism Questionnaire. Personality and Individual Differences, 52(8), 865-869. https:// doi.org/10.1016/j.paid.2012.02.003

Dooley, D., Prause, J., Ham-Rowbottom, K. A., \& Emptage, N. (2005). Age of alcohol drinking onset: Precursors and the mediation of alcohol disorder. Journal of Child and Adolescent Substance Abuse, 15(2), 19-37. https://doi.org/10.1300/J029v15n02_02

Driscoll, R. (1989). Self-condemnation: A comprehensive framework for assessment and treatment. Psychotherapy Theory Research Practice Training, 26(1), 104-111. https://doi.org/10.1037/h0085394

Dunkley, D. M., Berg, J. L., \& Zuroff, D. C. (2012). The role of perfectionism in daily self-esteem, attachment, and negative affect. Journal of Personality, 80(3), 633-663. https://doi.org/10.1111/j. 1467-6494.2011.00741.x

Dunkley, D. M., Blankstein, K. R., Masheb, R. M., \& Grilo, C. M. (2006). Personal standards and evaluative concerns dimensions of "clinical" perfectionism: A reply to Shafran et al. $(2002,2003)$ and Hewitt et al. (2003). Behaviour Research and Therapy, 44(1):63-84. https://doi.org/10.1016/j.brat. 2004.12.004

Dunkley, D. M., \& Grilo, C. M. (2007). Self-criticism, low self-esteem, depressive symptoms, and overevaluation of shape and weight in binge eating disorder patients. Behaviour Research and Therapy, 45(1), 139-149. https://doi.org/10.1016/j.brat.2006.01.017

Dunkley, D. M., Zuroff, D. C., \& Blankstein, K. R. (2003). Self-critical perfectionism and daily affect: Dispositional and situational influences on stress and coping. Journal of Personality and Social Psychology, 84(1), 234-252. https://doi.org/10.1037/0022-3514.84.1.234

Egan, S. J., Hattaway, M., \& Kane, R. T. (2014). The relationship between perfectionism and rumination in post traumatic stress disorder. Behavioural and Cognitive Psychotherapy, 42(2), 211-223. https://doi.org/10.1017/S1352465812001129

Fergus, T. A., \& Bardeen, J. R. (2016). The attention training technique: A Review of a neurobehavioral therapy for emotional disorders. Cognitive and Behavioral Practice, 23(4), 502-516. https://doi. org/10.1016/j.cbpra.2015.11.001

Fergus, T. A., Wheless, N. E., \& Wright, L. C. (2014). The attention training technique, self-focused attention, and anxiety: A laboratory-based component study. Behaviour Research and Therapy, 61, 150-155. https://doi.org/10.1016/j.brat.2014.08.007

Flett, G. L., Hewitt, P. L., Blankstein, K., \& O’Brien, S. (1991). Perfectionism and learned resourcefulness in depression and self-esteem. Personality and Individual Differences, 12(1), 61-68. https:// doi.org/10.1016/0191-8869(91)90132-U

Flett, G. L., Madorsky, D., Hewitt, P. L., \& Heisel, M. J. (2002). Perfectionism cognitions, rumination, and psychological distress. Journal of Rational-Emotive and Cognitive-Behavior Therapy, 20(1), 33-47. https://doi.org/10.1023/A:1015128904007

Flett, G. L., Russo, F. A., \& Hewitt, P. L. (1994). Dimensions of perfectionism and constructive thinking as a coping response. Journal of Rational-Emotive and Cognitive-Behavior Therapy, 12(3), 163-179. https://doi.org/10.1007/BF02354594

Folkman, S. (2013). Stress: Appraisal and coping. In M. D. Gellman \& J. R.Turner (eds), Encyclopedia of Behavioral Medicine. New York, NY: Springer. https://doi.org/10.1007/978-1-4419-1005-9_215

Frost, R. O., Heimberg, R. G., Holt, C. S., Mattia, J. I., \& Neubauer, A. L. (1993). A comparison of two measures of perfectionism. Personality and Individual Differences, 14(1), 119-126. https://doi.org/ 10.1016/0191-8869(93)90181-2

Frost, R. O., Lahart, C. M., \& Rosenblate, R. (1991). The development of perfectionism: A study of daughters and their parents. Cognitive Therapy and Research, 15(6), 469-489. https://doi.org/10. 1007/BF01175730 
Frost, R. O., Marten, P., Lahart, C., \& Rosenblate, R. (1990). The dimensions of perfectionism. Cognitive Therapy and Research, 14(5), 449-468. https://doi.org/10.1007/BF01172967

Gkika, S., \& Wells, A. (2015). How to deal with negative thoughts? A preliminary comparison of detached mindfulness and thought evaluation in socially anxious individuals. Cognitive Therapy and Research, 39(1), 23-30. https://doi.org/10.1007/s10608-014-9637-5

Grzegorek, J. L., Slaney, R. B., Franze, S., \& Rice, K. G. (2004). Self-criticism, dependency, self-esteem, and grade point average satisfaction among clusters of perfectionists and nonperfectionists. Journal of Counseling Psychology, 51(2), 192-200. https://doi.org/10.1037/0022-0167.51.2.192

Gual, P., Prez-Gaspar, M., Martnez-Gonzlez, M. A., Lahortiga, F., De Irala-Estvez, J., \& Cervera-Enguix, S. (2002). Self-esteem, personality, and eating disorders: Baseline assessment of a prospective population-based cohort. International Journal of Eating Disorders, 31(3), 261-273. https://doi.org/ 10.1002/eat. 10040

Hall, H. K., Kerr, A. W., \& Matthews, J. (1998). Precompetitive anxiety in sport: The contribution of achievement goals and perfectionism. Journal of Sport and Exercise Psychology, 20(2), 194217. https://doi.org/10.1123/jsep.20.2.194

Hamachek, D. E. (1978). Psychodynamics of normal and neurotic perfectionism. Psychology A Journal of Human Behavior, 15(1), 27-33.

Hayes, A. F. (2013). Methodology in the social sciences: Introduction to mediation, moderation, and conditional process analysis: A regression-based approach. Guilford Press.

Heimpel, S. A., Wood, J. V., Marshall, M. A., \& Brown, J. D. (2002). Do people with low self-esteem really want to feel better? Self-esteem differences in motivation to repair negative moods. Journal of Personality and Social Psychology, 82(1), 128-147. https://doi.org/10.1037/0022-3514. 82.1.128

Henning, E. R., Turk, C. L., Mennin, D. S., Fresco, D. M., \& Heimberg, R. G. (2007). Impairment and quality of life in individuals with generalized anxiety disorder. Depression and Anxiety, 24(5), 342-349. https://doi.org/10.1002/da.20249

Hewitt, P. L., \& Flett, G. L. (1991). Perfectionism in the self and social contexts: Conceptualization, assessment, and association with psychopathology. Journal of Personality and Social Psychology, 60(3), 456-470. https://doi.org/10.1037/0022-3514.60.3.456

Hollender, M. H. (1965). Perfectionism. Comprehensive Psychiatry, 6(2), 94-103. https://doi.org/10. 1016/S0010-440X(65)80016-5

Horney, K. (1991). Neurosis and human growth: The struggle toward self-realization. WW Norton \& Company.

IBM Corp. (2019). IBM SPSS Statistics for Windows, Version 26.

James, K., Verplanken, B., \& Rimes, K. A. (2015). Self-criticism as a mediator in the relationship between unhealthy perfectionism and distress. Personality and Individual Differences, 79, 123128. https://doi.org/10.1016/j.paid.2015.01.030

Joreskog, K. G., \& Sorbom, D. (1996). LISREL 8: User's reference guide. Scientific Software International.

Knowles, M. M., Foden, P., El-Deredy, W., \& Wells, A. (2016). A systematic review of efficacy of the Attention Training Technique in clinical and nonclinical samples. Journal of Clinical Psychology, 72(10), 999-1025. https://doi.org/10.1002/jclp.22312

Kolubinski, D. C., Marino, C., Nikčević, A. V., \& Spada, M. M. (2019). A metacognitive model of self-esteem. Journal of Affective Disorders, 256, 42-53. https://doi.org/10.1016/j.jad.2019.05. 050

Kolubinski, D. C., Nikčević, A. V., Lawrence, J. A., \& Spada, M. M. (2016). The role of metacognition in self-critical rumination: An investigation in individuals presenting with low self-esteem. Journal of Rational-Emotive \& Cognitive-Behavior Therapy, 34(1), 73-85. https://doi.org/10. 1007/s10942-015-0230-y

Kolubinski, D. C., Nikčević, A. V., Lawrence, J. A., \& Spada, M. M. (2017). The metacognitions about self-critical rumination questionnaire. Journal of Affective Disorders, 220, 129-138. https://doi. org/10.1016/j.jad.2017.06.002

Kugu, N., Akyuz, G., Dogan, O., Ersan, E., \& Izgic, F. (2006). The prevalence of eating disorders among university students and the relationship with some individual characteristics. Australian and New Zealand Journal of Psychiatry, 40(2), 129-135. https://doi.org/10.1111/j.1440-1614.2006.01759.x

Kuster, F., Orth, U., \& Meier, L. L. (2013). High self-esteem prospectively predicts better work conditions and outcomes. Social Psychological and Personality Science, 4(6), 668-675. https://doi.org/ $10.1177 / 1948550613479806$ 
Kutner, M. H., Nachtsheim, C. J., \& Neter, J. (2004). Applied linear regression models (4th ed.). McGraw-Hill Irwin.

Leary, M. R., Tambor, E. S., Terdal, S. K., \& Downs, D. L. (1995). Self-esteem as an interpersonal monitor: The sociometer hypothesis. Journal of Personality and Social Psychology, 68(3), 518-530. https://doi.org/10.1037/0022-3514.68.3.518

Lyubomirsky, S., \& Nolen-Hoeksema, S. (1995). Effects of self-focused rumination on negative thinking and interpersonal problem solving. Journal of Personality and Social Psychology, 69(1), 176-190. https://doi.org/10.1037/0022-3514.69.1.176

Marx, R. W., \& Winne, P. H. (1978). Construct interpretations of three self-concept inventories. American Educational Research Journal, 15(1), 99-109. https://doi.org/10.3102/00028312015001099

Moreira, H., \& Canavarro, M. C. (2018). The association between self-critical rumination and parenting stress: The mediating role of mindful parenting. Journal of Child and Family Studies, 27(7), 2265-2275. https://doi.org/10.1007/s10826-018-1072-x

Mouratidis, A., \& Michou, A. (2011). Perfectionism, self-determined motivation, and coping among adolescent athletes. Psychology of Sport and Exercise, 12(4), 355-367. https://doi.org/10.1016/j.psych sport.2011.03.006

Nolen-Hoeksema, S., Wisco, B. E., \& Lyubomirsky, S. (2008). Rethinking rumination. Perspectives on Psychological Science, 3(5), 400-424.

Nordahl, H., Nordahl, H. M., Hjemdal, O., \& Wells, A. (2017). Cognitive and metacognitive predictors of symptom improvement following treatment for social anxiety disorder: A secondary analysis from a randomized controlled trial. Clinical Psychology and Psychotherapy, 24(6), 1221-1227. https:// doi.org/10.1002/cpp. 2083

O'Connor, D. B., O’Connor, R. C., \& Marshall, R. (2007). Perfectionism and psychological distress: Evidence of the mediating effects of rumination. European Journal of Personality, 21(4), 429-452. https://doi.org/10.1002/per.616

Ormel, J., Oldehinkel, A. J., \& Vollebergh, W. (2004). Vulnerability before, during, and after a major depressive episode: A 3-wave population-based study. Archives of General Psychiatry, 61(10), 990-996. https://doi.org/10.1001/archpsyc.61.10.990

Orth, U., \& Robins, R. W. (2019). Development of self-esteem across the lifespan. In D. P. McAdams, R. L. Shiner, \& J. L. Tackett (Eds.), Handbook of personality development. Guilford.

Orth, U., Robins, R. W., \& Meier, L. L. (2009). Disentangling the effects of low self-esteem and stressful events on depression: Findings from three longitudinal studies. Journal of Personality and Social Psychology, 97(2), 307-321. https://doi.org/10.1037/a0015645

Orth, U., Robins, R. W., Meier, L. L., \& Conger, R. D. (2016). Refining the vulnerability model of low self-esteem and depression: Disentangling the effects of genuine self-esteem and narcissism. Journal of Personality and Social Psychology, 110, 133-149. https://doi.org/10.1037/pspp0000038

Orth, U., Robins, R. W., \& Widaman, K. F. (2012). Life-span development of self-esteem and its effects on important life outcomes. Journal of Personality and Social Psychology, 102(6), 1271-1288. https://doi.org/10.1037/a0025558

Papageorgiou, C., \& Wells, A. (2001a). Metacognitive beliefs about rumination in recurrent major depression. Cognitive and Behavioral Practice, 8(2), 160-164. https://doi.org/10.1016/S10777229(01)80021-3

Papageorgiou, C., \& Wells, A. (2001b). Positive beliefs about depressive rumination: Development and preliminary validation of a self-report scale. Behavior Therapy, 32(1), 13-26. https://doi.org/10. 1016/S0005-7894(01)80041-1

Park, H., Heppner, P. P., \& Lee, D. (2010). Maladaptive coping and self-esteem as mediators between perfectionism and psychological distress. Personality and Individual Differences, 48(4), 469-474. https://doi.org/10.1016/j.paid.2009.11.024

Park, L. E., \& Crocker, J. (2013). Pursuing self-esteem: Implications for self-regulation and relationships. In V. Zeigler-Hill (Ed.), self-esteem (pp. 43-59). Psychology Press. https://doi.org/10.4324/97802 03587874

Parker, W. D. (1997). An empirical typology of perfectionism in academically talented children. American Educational Research Journal, 34(3), 545-562. https://doi.org/10.3102/00028312034003545

Pratt, E. M., Telch, C. F., Labouvie, E. W., Terence Wilson, G., \& Stewart Agras, W. (2001). Perfectionism in women with binge eating disorder. International Journal of Eating Disorders, 29(2), 177-186.

Preusser, K. J., Rice, K. G., \& Ashby, J. S. (1994). The role of self-esteem in mediating the perfectionism-depression connection. Journal of College Student Development, 35(2), 88-93. 
R Development Core, T. (2017). R: A language and environment for statistical computing. R Foundation for Statistical Computing, Vienna, Austria. ISBN 3-900051-07-0, http://www.R-project.org/. https://doi.org/10.1007/978-3-540-74686-7

Rice, K. G., Ashby, J. S., \& Slaney, R. B. (1998). Self-esteem as a mediator between perfectionism and depression: A structural equations analysis. Journal of Counseling Psychology, 45(3), 304-314. https://doi.org/10.1037/0022-0167.45.3.304

Rosenberg, M. (1965). Society and the adolescent self-image. Princeton University Press.

Rosenberg, M., Schooler, C., Schoenbach, C., \& Rosenberg, F. (1995). Global self-esteem and specific self-esteem: Different concepts, different outcomes. American Sociological Review, 60(1), 141. https://doi.org/10.2307/2096350

Satorra, A., \& Bentler, P. M. (1994). Corrections to test statistics and standard errors in covariance structure analysis. In A. Von Eye \& C. C. Clogg (Eds.), Latent variable analysis. Applications for developmental research (pp. 399-419). Sage.

Shafran, R., Cooper, Z., \& Fairburn, C. G. (2002). Clinical perfectionism: A cognitive-behavioural analysis. Behaviour Research and Therapy, 40(7), 773-791. https://doi.org/10.1016/S0005-7967(01) 00059-6

Shahar, G. (2015). Erosion: The psychopathology of self-criticism. Oxford University Press.

Shahar, G., \& Davidson, L. (2003). Depressive symptoms erode self-esteem in severe mental illness: A three-wave, cross-lagged study. Journal of Consulting and Clinical Psychology, 71(5), 890-900. https://doi.org/10.1037/0022-006X.71.5.890

Shahar, G., \& Henrich, C. C. (2010). Do depressive symptoms erode self-esteem in early adolescence? Self and Identity, 9(4), 403-415. https://doi.org/10.1080/15298860903286090

Sheather, S. (2009). A modern approach to regression with $R$. New York, NY: Springer.

Simpson, C., \& Papageorgiou, C. (2003). Metacognitive beliefs about rumination in anger. Cognitive and Behavioral Practice, 10(1), 91-94. https://doi.org/10.1016/S1077-7229(03)80012-3

Smart, L. M., Peters, J. R., \& Baer, R. A. (2016). Development and validation of a measure of self-critical rumination. Assessment, 23(3), 321-332. https://doi.org/10.1177/1073191115573300

Solem, S., Håland, Å. T., Vogel, P. A., Hansen, B., \& Wells, A. (2009). Change in metacognitions predicts outcome in obsessive-compulsive disorder patients undergoing treatment with exposure and response prevention. Behaviour Research and Therapy, 47(4), 301-307. https://doi.org/10.1016/j. brat.2009.01.003

Sorotzkin, B. (1985). The quest for perfection: Avoiding guilt or avoiding shame? Psychotherapy, 22(3), 564-571. https://doi.org/10.1037/h0085541

Sowislo, J. F., \& Orth, U. (2013). Does low self-esteem predict depression and anxiety? A meta-analysis of longitudinal studies. Psychological Bulletin, 139(1), 213-240. https://doi.org/10.1037/a0028931

Spada, M. M., Giustina, L., Rolandi, S., Fernie, B. A., \& Caselli, G. (2014). Profiling metacognition in gambling disorder. Behavioural and Cognitive Psychotherapy, 43(5), 614-622. https://doi.org/10. $1017 / \mathrm{S} 1352465814000101$

Spada, M. M., \& Wells, A. (2006). Metacognitions about alcohol use in problem drinkers. Clinical Psychology \& Psychotherapy, 13, 138-143. https://doi.org/10.1002/cpp.478

Stinson, D. A., Logel, C., Zanna, M. P., Holmes, J. G., Cameron, J. J., Wood, J. V., \& Spencer, S. J. (2008). The cost of lower self-esteem: Testing a self- and social-bonds model of health. Journal of Personality and Social Psychology, 94(3), 412. https://doi.org/10.1037/0022-3514.94.3.412

Stoeber, J., \& Damian, L. E. (2014). The Clinical Perfectionism questionnaire: Further evidence for two factors capturing perfectionistic strivings and concerns. Personality and Individual Differences, 61-62, 38-42. https://doi.org/10.1016/j.paid.2014.01.003

Stoeber, J., \& Otto, K. (2006). Positive conceptions of perfectionism: Approaches, evidence, challenges. Personality and Social Psychology Review, 10(4), 295-319. https://doi.org/10.1207/s15327957p spr1004_2

Taylor, J. J., Papay, K. A., Webb, J. B., \& Reeve, C. L. (2016). The good, the bad, and the interactive: Evaluative concerns perfectionism moderates the effect of personal strivings perfectionism on selfesteem. Personality and Individual Differences, 95, 1-5. https://doi.org/10.1016/j.paid.2016.02.006

Treynor, W., Gonzalez, R., \& Nolen-Hoeksema, S. (2003). Rumination reconsidered: A psychometric analysis. Cognitive Therapy and Research, 27(3), 247-259. https://doi.org/10.1023/A:1023910315 561

Trzesniewski, K. H., Donnellan, M. B., Moffitt, T. E., Robins, R. W., Poulton, R., \& Caspi, A. (2006). Low self-esteem during adolescence predicts poor health, criminal behavior, and limited economic 
prospects during adulthood. Developmental Psychology, 42(2), 381-390. https://doi.org/10.1037/ 0012-1649.42.2.381

Trzesniewski, K. H., Donnellan, M. B., \& Robins, R. W. (2003). Stability of self-esteem across the life span. Journal of Personality and Social Psychology, 84(1), 205-220. https://doi.org/10.1037/00223514.84.1.205

Wells, A. (2000). Emotional disorders and metacognition: Innovative cognitive therapy. Wiley.

Wells, A. (2005). Detached mindfulness in cognitive therapy: A metacognitive analysis and ten techniques. Journal of Rational-Emotive \& Cognitive-Behavior Therapy, 23(4), 337-355. https://doi. org/10.1007/s10942-005-0018-6

Wells, A. (2009). Metacognitive therapy for anxiety and depression. Guilford Press.

Wells, A. (2013). Advances in metacognitive therapy. International Journal of Cognitive Therapy, 6(2), 186-201. https://doi.org/10.1521/ijct.2013.6.2.186

Wells, A., \& Colbear, J. S. (2012). Treating posttraumatic stress disorder with metacognitive therapy: A preliminary controlled trial. Journal of Clinical Psychology, 68(4), 373-381. https://doi.org/10. 1002/jclp.20871

Wells, A., \& Matthews, G. (1996). Modelling cognition in emotional disorder: The S-REF model. Behaviour Research and Therapy, 34(11-12), 881-888. https://doi.org/10.1016/S0005-7967(96)00050-2

Wells, A., Welford, M., King, P., Papageorgiou, C., Wisely, J., \& Mendel, E. (2010). A pilot randomized trial of metacognitive therapy vs applied relaxation in the treatment of adults with generalized anxiety disorder. Behaviour Research and Therapy, 48(5), 429-434. https://doi.org/10.1016/j.brat. 2009.11.013

Werner, A. M., Tibubos, A. N., Rohrmann, S., \& Reiss, N. (2019). The clinical trait self-criticism and its relation to psychopathology: A systematic review-Update. Journal of Affective Disorders, 246, 530-547. https://doi.org/10.1016/j.jad.2018.12.069

Woike, B. A., \& Baumgardner, A. H. (1993). Global-specific incongruencies in self-worth and the search for self-knowledge. Personality and Social Psychology Bulletin, 19(3), 290-295. https://doi.org/10. $1177 / 0146167293193005$

Young, E. A., \& Nolen-Hoeksema, S. (2001). Effect of ruminations on the saliva cortisol response to a social stressor. Psychoneuroendocrinology, 26(3), 319-329. https://doi.org/10.1016/S03064530(00)00059-7

Zuroff, D. C., Moskowitz, D. S., \& Côté, S. (1999). Dependency, self-criticism, interpersonal behaviour and affect: Evolutionary perspectives. British Journal of Clinical Psychology, 38(3), 231-250. https://doi.org/10.1348/01446659916282

Publisher's Note Springer Nature remains neutral with regard to jurisdictional claims in published maps and institutional affiliations. 